\title{
Teacher help for conceptual level raising in mathematics
}

\author{
Monique Pijls · Rijkje Dekker · Bernadette Van Hout-Wolters
}

Received: 17 January 2006/Accepted: 4 September 2006/Published online: 6 October 2007

(C) Springer Science+Business Media B.V. 2007

\begin{abstract}
A field study with 16-year-old students in senior general secondary education was undertaken with the following research question: "Do students working in pairs on investigation tasks with the computer attain more conceptual level raising in mathematics when they are supported by a teacher who stimulates their interaction (process help) than when they are supported by a teacher who gives mathematical help (product help)?" Students in both conditions improved, but the two types of help showed no significant difference in level raising. Also, students in both conditions had serious problems with the learning materials, and wanted the teacher to explain and correct more. For students at this level of education, learning with investigation tasks in small groups appears to be very difficult.
\end{abstract}

Keywords Collaborative learning - Conceptual level raising - Mathematics education · Teacher help

\section{Introduction}

Guiding students by teachers in a collaborative learning process means creating optimal conditions in which they can learn from one another. Within the context of a mathematics lesson, the issue is whether the teacher should stay away from the mathematical content of what students are saying and focus on their interactions, or whether the teacher should provide mathematical hints when students ask for help. Generally speaking, should a teacher leave the learning content to the students and keep watch on the collaborative

M. Pijls $(\bowtie) \cdot$ R. Dekker $\cdot$ B. Van Hout-Wolters

Graduate School of Teaching and Learning, University of Amsterdam, Spinozastraat 55, Amsterdam 1018 HJ, The Netherlands

e-mail: m.h.j.pijls@uva.nl

R. Dekker

e-mail: r.dekker@uva.nl

B. Van Hout-Wolters

e-mail: b.h.a.m.vanhout-wolters@uva.nl 
learning process, or take part in the collaboration by focusing on the content of what has to be learned?

This study is the second part of a research project entitled Mathematical Investigation Tasks with the Computer that deals with the question of how students can best learn mathematical concepts when they are working on collaborative investigation tasks with the computer. This question is answered for 16-year-old students in senior general secondary education for the subject of probability theory. Earlier research has made it clear that the students in senior general secondary education who have to take obligatory courses on applied mathematics were not always motivated to perform investigations with the computer. The findings for these students were the opposite to those for students in preuniversity education and senior general secondary education who chose pure mathematics ${ }^{1}$ (Niemiec et al. 1996; Prent 1999; PRINT 1998; Schnackenberg 2000). In an earlier study (Pijls et al. 2003), we developed collaborative investigation tasks around a computer simulation, which we made very accessible for students in order to motivate them. In this study, we investigated which type of teacher help is most conducive to learning mathematics with these materials. Any results could lead to hypotheses about guiding students who are learning mathematics, or any other subject, collaboratively.

\section{Theoretical background}

\section{Teacher help for collaborative learning}

Collaborative learning is fruitful for students if it gives them the opportunity to sharpen their own thinking (Davidson 1990; Dekker 1994; Dekker and Elshout-Mohr 2004; Webb 1991). The quality of students' interactions is influenced by several factors, such as the learning materials, the composition of the groups, and the role of the teacher. In this study, we focused on this last aspect. We built on a study performed by Dekker and Elshout-Mohr (2004), which is extensively discussed in a later section. They compared the effect on conceptual level raising in mathematics of a teacher who focused on the students' interactions with a teacher who paid attention to the mathematical content of the students' work.

Several studies showed the positive effect of instruction on students' achievements in collaborative learning settings. Kramarski et al. (2002) concluded that cooperative learning in combination with a metacognitive instruction led to better learning results than cooperative learning in combination with 'regular' instruction with cooperative learning. Hoek (1998) found positive effects of instruction including social and cognitive strategies on the learning results for both types of instruction, but no additive effect of the two. In an experiment lasting 1 year, Hoek and Seegers (2005) found that instructional activities, including modelling problem solving, stimulating reflection and giving feedback about the process of collaboration, were effective for collaborative problem solving. Hughes and

\footnotetext{
1 Secondary education encompasses schools providing pre-university education (VWO), senior general secondary education (HAVO), pre-vocational secondary education (VMBO) and Practical Training (PRO). All four types of secondary education are for children aged 12 years and over and all begin with a period of basic secondary education. In 1999, all HAVO and VWO schools introduced set subject combinations and the 'study house' construction, which commences in the fourth course year and requires students to acquire skills and knowledge in a much more independent way. We speak of 'obligatory' mathematics, because all subject combinations include applied mathematics, while only the technical and science subject combinations include pure mathematics.
} 
Greenhough (1995) compared children working on a computer task about a turtle following Logo commands in four conditions: (a) alone; (b) with a peer; (c) with an adult; and (d) with a peer and an adult. The software used gave feedback to the children if they did not act correctly. The adults let the children make some errors before giving helpful advice. The results of the study showed no significant differences due to the conditions in terms of posttest gains. They concluded that feedback from an adult and collaboration were not additive in their effects on learning. This last study, however, involved a learning environment with very strong feedback ('error' notifiers in a computer program) about mistakes in the learning materials.

Although the teacher's instruction involving group work turns out to be fruitful in several studies, Wood (2001) stresses that teachers should stay away from the students' discussions in order to create situations in which students can construct their own knowledge. This is not an easy job for teachers, because they might experience a strong (human) tendency to explain, as she mentions in the following passage:

As advocated in the reform documents, learning mathematics with understanding is thought to occur best in situations in which children are expected to problem solve, reason, and communicate their ideas and thinking to others. Moreover, it is thought that situations of confusion and clash of ideas in which students are allowed to struggle to resolution are precisely the settings that promote learning with understanding. Therefore, (...) teachers must resist their natural inclination to tell students information, make the task simpler, or step in and do part of the task. (Wood 2001, p. 116)

Another obstacle for teachers in supporting students' collaborative learning lies in the fact that the teacher cannot hear what the students are saying while working on the task. Brodie (2001) describes this problem. For teachers it is difficult to give appropriate mathematical hints that fit every single student because they do not follow the discussion taking place between students. A mathematical hint could hinder the students' own thinking process. In order to avoid this, teachers might focus on the process of mathematical reasoning in order to make students explain their work to one another and to criticise one another.

Marzi (2003) and Veenhoven (2004) also distinguish between teacher help that focuses on the content of what has to be learned and teacher help that focuses on the students' learning process without guiding the content of what has to be learned. Marzi (2003) investigated the difference between students working collaboratively under the guidance of a supportive adult (with the role of giving students feedback about their progress in structuring the task and solving the test, but refraining from intervening in their problem solving) and an instructive adult (maintaining students' involvement, but also focusing their attention on the steps required to solve the test and directing their actions to the task goal). It was found that students working with the supportive adult showed significantly more clear explanations and theoretical approaches than students working with the instructive adult. The adult's abstention from interfering with the content of the group work appeared to be beneficial to the students' learning.

In a different educational setting, Veenhoven (2004) examined which components of the teacher's helping behaviour contributed to the student's investigation skills. His study was carried out with 16-year-old students in secondary education working on collaborative investigation tasks for the subject of geography. The students were followed while they were working on these tasks. It was shown that support of the students' interactions led to better learning results than support of the learning content. 
The two studies mentioned above show that, when an adult does not interfere with the content of the tasks but stimulates the process of interaction between students, the students achieve higher learning scores.

\section{Mathematical level raising}

We operationalise the learning of mathematics as attaining conceptual level raising (cf. Van Hiele 1986). When a topic is new for students, they will approach it at the perceptual level, according to their prior knowledge or naive knowledge of the domain. By reflecting on both their own and one another's work, they will develop a structure in a certain domain and approach the subject at a conceptual level: level raising has taken place. Conceptual level raising is defined for a certain concept, so an approach can occur at the conceptual level with respect to one concept and at the perceptual level with respect to another.

To stimulate the learning process, it is important to connect the learning materials to the students' starting level and to create possibilities for level raising. In our project, we use computer games with an underlying mathematical structure in order to have a connection to the perceptual level. The tasks accompanying computer simulations aim at the conceptual level. Students start with the gambling game Plinko and they finish with calculating probabilities with the help of Pascal's triangle.

In order to give rise to discussions between students, the learning materials must conform to certain criteria (Dekker 1994). The materials have to be real or meaningful to motivate and stimulate the students, to be complex in order to make the students need one another, to involve constructing something in order to make the different thoughts visible and objects for discussion, and to aim at level raising. We expect the collaboration with peers to stimulate reflection and to induce level raising. Dekker and Elshout-Mohr (1998) developed a process model in which they describe the interactions between students that lead to conceptual level raising. They distinguish students' key activities of:

- Showing one's work

- Explaining one's work

- Justifying one's work

- Reconstructing one's work.

All of those activities are evidently related to reflection, either because they give rise to reflection (showing and explaining one's work) or because they are the result of it (justifying and reconstructing). Students can evoke these key activities among one another by regulating activities: to ask one another to show one's work; to ask one another to explain one's work; and to criticise one another's work. The situation described in the process model is that of a small group of students working together on the same mathematical problem. The work of the students is assumed to be different.

Process help and product help

When students have full opportunities to learn with one another and with the especially developed learning materials, the teacher's help can be minimal. Dekker and Elshout-Mohr (2004) investigated what kind of minimal help from the teacher was most beneficial to students in terms of attaining level raising for students in the fifth year of pre-university 
education. The students were working in heterogeneous triads on investigation tasks on the subject of geometrical transformations. Two types of teacher help were compared:

1. Product help: teacher's help focused on the quality of the mathematical product on which students are working (mathematical hints).

2. Process help: teacher's help focused on the quality of the interaction between students.

It turned out that the 'product students' made more products at a conceptual level during the lessons than did the 'process students'. However, the 'process students' attained significantly more level raising in the posttest than 'product students'. Dekker and ElshoutMohr explained this in terms of the 'process teacher' not disturbing the thinking process of the students. The teacher only kept the interaction going and hence created an opportunity for reflection, but did not interfere with the students' thinking. The 'product teacher' disturbed the students' thinking with mathematical hints, because he/she could not follow the whole discussion of the students. The product teacher focused on the products of the students.

In this study, we investigated the effect of process and product help for another level of education than in Dekker and Elshout-Mohr's study. Our research project closely relates to their study. Both projects deal with students working in groups, with the groups composed in such a way that there are differences in mathematical level between students. In both projects, learning materials were developed for collaborative learning according to the four criteria mentioned in the previous section (meaningful; complex; involve constructing something; aimed at level raising). The learning materials contained no 'theory blocks' (i.e. sections in which a mathematical concept was shown and explained) and no 'correction sheets' with the correct answers to assess their work afterwards (the students corrected their work with the help of correction sheets after finishing the tasks). No classroom discussions took place in either project.

Besides the similarities, there are differences between Dekker and Elshout-Mohr's study and ours. We used a computer simulation in order to give students the opportunity to reflect on concrete experiences, whereas Dekker and Elshout-Mohr used pencil-and-paper tasks and concrete geometrical shapes. The size of the groups differed, because Dekker and Elshout-Mohr studied triads and we studied dyads. In principle, we expect that, in a group of three peers, more discussion would occur than in a dyad but, because three students cannot work on one computer at a time, we chose dyads. Another difference lay in the type of education (pre-university versus senior general secondary) and the kind of mathematics (students who chose to study pure mathematics in Dekker and Elshout-Mohr's study versus students who mainly had obligatory applied mathematics in our study). The opinion of many teachers is that students in pre-university education are much more inclined to investigate than students in senior general secondary education. The same holds for the pure mathematics students versus the applied mathematics students. A final difference was the length of the experiment (two lessons of 65 min in Dekker and Elshout-Mohr's study versus six lessons of $40 \mathrm{~min}$ in our study).

Aim of the study

We undertook this experiment in order to answer the following question: "Do students in Grade 10 of senior general secondary education who work in pairs on investigation tasks with the computer attain more conceptual level raising when they are supported by a 
teacher who provides process help than when they are supported by a teacher who provides product help?"

This question was answered by a pretest and posttest analysis. We expected the process help to lead to more conceptual level raising, because process help promotes students to perform key activities (to show, explain, justify and reconstruct one's work), which in turn leads to conceptual level raising. Based on Dekker and Elshout-Mohr's results, we expected product help to disturb the process of conceptual level raising, because it keeps students from executing key activities and, hence, denies them an opportunity for conceptual level raising.

\section{Method}

\section{Participants}

Two mathematics classes and their teachers from the fourth year of senior general secondary education participated in our experiment. It involved 52 students (53 minus one student who did not complete the posttest). The school, a Montessori school in Amsterdam, had been selected on account of their experience with students working independently and the motivation of the teachers to take part in the experiment. We chose this school in order to have students and teachers who already were used to a situation as close as possible to the experimental roles. Students were used to plan their own work, for example. The experiment took place in the school and consisted of 6-8 lessons of $40 \mathrm{~min}$ (depending on how much time a pair of students needed).

Pretest, composition of the two experimental groups and posttest

One week before the experimental lessons started, the students undertook a pretest consisting of 12 open-ended paper-and-pencil questions, with a total maximum score of 46 points. It contained four items that tested prior knowledge of probability theory (total of 11 points) and eight items about the subject of Routes and Probabilities (total of 35 points). The eight questions about the subject of Routes and Probabilities were spread out over four subtopics (Counting Routes in a Grid, Calculating Probabilities in a Grid, Solving Counting Problems with the Help of the Grid as a Model, and Solving Probability Problems with the Grid as a Model). An example of an item for the subtopic Calculating Probabilities in a Grid is given in the Appendix. Because these questions tested the knowledge that students had to learn, we did not expect them to answer all these questions correctly. We made this clear in some hints, like: "The following question is a bit more complicated. Give it a try!" The reliability of the pretest was adequate (Cronbach's $\alpha=0.68$ ). One person coded all the pretests and another person coded $10 \%$ of all the pretests. The interjudge reliability was $96 \%$.

We used the results of the test to assign participants to two condition groups that were comparable with regard to their pretest results and that contained an equal number of students from each class. This was done in order to avoid confounding teacher effects. There were no indications that one of the teachers was more liked by students than the other. We also used the pretest results in order to compose semi-heterogeneous pairs of students: pairs consisting of an average and a high-level student, or an average and a lowlevel student (in order to have differences between students not being too large). The pairs 
were composed by the researcher and modified by the teachers in cases in which some students were expected not to be able to cooperate with one another (for instance, a very shy girl who had asked her teacher not to be linked up with very extravert students).

At the end of all the lessons, the students undertook a posttest. The open-ended questions in this posttest were very similar to the pretest. The number of questions and the division of points were the same and the questions often had very similar contexts. This time, however, we expected the students to be able to master the majority of the tasks. The reliability of the posttest was adequate (Cronbach's $\alpha=0.77$ ). One person coded all the posttests. Another person coded $10 \%$ of all the posttests and the interjudge reliability was 96\%. The results of the pretests and posttests were used to analyse differences in conceptual level raising between the two condition groups.

\section{Learning materials}

The learning materials consisted of a computer simulation with accompanying collaborative investigation tasks (to be solved with paper and pencil) on the subject of Routes and Probabilities. Any domain of science or mathematics could have been selected, but this part of probability theory was chosen because it has both a visual and an abstract component. The computer simulation was composed of simple (gambling) games with the underlying structure of a grid (a mathematical concept for counting possibilities and calculating probabilities). An example of such a game is TIC-TAC, as shown in Fig. 1.

Students were asked if they had a winning strategy for the game TIC-TAC, and then they got the investigation task: "What is the probability for a ball to end up in the node with 100 points?" The idea of this question was that students would realise that the probability of ending up in a certain box was not equal for all. In the paper-and-pencil task that followed, both students (each drawing on a separate working sheet) had to



Fig. 1 The game TIC-TAC 
draw possible paths in the TIC-TAC gameboard from the starting point towards the box with the 100 points. Subsequently the students were asked to describe the paths in terms of RUURUUUU (with R meaning 'to the right' and U 'upwards') to compare them with their peers and to formulate what struck them. In the following tasks, the concept of 'counting routes in a grid' was developed. So the games were meant to create experiences with different grids and the tasks were intended to make students reflect on their experiences with the games and, hence, learn about mathematical grids. The same learning materials were used in both the product-help group and the processhelp group.

Preparing the roles of the teachers: Process help and product help

One month before the experiment started, the teachers received the learning materials. They discussed them and gave some useful hints for improvement. During two sessions, we prepared the two teacher roles. In the first session, the roles of the process and the product teacher were explained. The 'process teacher' provides no content-related help and stimulates the interaction between students. The initial instructions for process help to all students were:

I will not help you with content, but I want you to discuss a lot, to show your work to one another, to explain to one another (that's how you learn), and criticise one another, so that the work improves...

An example of process help to students who asked for help:

I want you to decide by yourselves, think about it, be critical towards one another's ideas.

The 'product teacher' only provides content-related help when asked for it and gives no hints for the interaction. The initial instructions of product help to all students were:

You will work on these tasks by yourselves; I am here to assist you.

Two examples of product help to students who asked for help:

Do you understand the picture?

Yes, $20 \%$ of this. Yes, both lines end up in the same box.

The researchers showed the behaviour of the two roles by means of role plays. Then we extensively discussed delicate aspects of each role. As a possible difficulty of process help, one of the teachers expected students to find it unacceptable if the teacher did not provide any explanation. Besides, they mentioned the risk of students not solving the tasks in the correct way. This risk was mentioned for product help too, because the teacher would only help the students if they asked. The facts that the learning materials were developed for interaction between students and that the product teacher was neglecting this aspect of the learning process were mentioned as an unnatural aspect of product help. Despite all these possible risks that their new roles in the classrooms could bring about, the teachers were very motivated and willing to take part in the experiment. We decided that both teachers should motivate their students to go to work if they were not willing to do this. In the next session, we discuss how we divided the 
roles and one of the teachers wanted to experiment with process help and the other fully agreed to provide product help. The teachers practised their roles by means of role plays.

\section{Data collection and analysis}

The utterances of both teachers during the experimental lessons were audiotaped and transcribed in order to check whether the help of the teachers was executed correctly. Furthermore it would give us the opportunity to analyse the help given by the teacher and the reactions of the students. Did they perform key activities?

During the study, one of the researchers observed alternately the 'product group' and the 'process group'. The following aspects were observed:

- Did the students interact with each other?

- Did the students ask the teacher for help?

- How did the teacher provide help?

- How did the students react on the teacher's help?

- Did the dyads interact with each other?

A focus of attention was the performance of key activities. Did the students show, explain, justify or reconstruct their work? The observations that were collected yielded a general impression of the course of the lessons.

At the end of each lesson, the researcher interviewed the teachers for $10 \mathrm{~min}$. They were asked how they experienced giving process or product help and what reactions they experienced from their students. The answers were written down and used to accomplish the analysis of the teacher's help.

At the end of all mathematical investigation tasks, the students were asked (on paper) what they had learned and whether they wanted to react to the experiment. Their written answers were collected and used to come to know the students' experience of the lessons.

\section{Results}

Course of the experiment

In general, the students of both conditions experienced the help of the teacher as very different from the normal situation. Although they were used to working independently, they expected the teacher to help them by providing explanations. In the process group, the teacher did not do this at all. With regard to a difficult task in the learning materials, many students arrived at an impasse in their learning process. This task was hard for them and many students were discouraged. The process teacher encouraged them to trust their own thinking. In the product group, the teacher always asked students to show their work before giving a mathematical hint. For some students, this was new, because they expected the teacher to give explanations when they told him: "I don't understand." During the second lesson, many students in the product condition arrived at a difficult task in which they had to reflect on the previous tasks and use the information in a more abstract way. This was hard for them and they asked the teacher for help. He could not help all students at the 
same time and some of them had to wait for a long time. This made the students feel that the teacher did not provide enough help.

\section{Checking of the implementation of teacher help}

By analysing the transcripts of what the teachers said, we checked whether the two types of help had been implemented as we had intended. The general conclusion was that this was indeed the case. Both teachers forgot their role only a few times and minimally even then. Both teachers helped their students to keep going. The product teacher did this by giving students explanations, sometimes rather extended ones. The process teacher tried to make his students think for themselves, encouraging them and giving them confidence. He referred to key activities (see earlier section), especially giving explanations to one another. Sometimes it was very difficult for him to avoid giving mathematical hints, especially when the students said that they both had no idea of what the answer was. Students were concerned about the test and the process teacher reassured them. Both teachers were very dedicated.

\section{Results of pretest and posttest}

We analysed the results of the pretest and the posttest in order to determine whether the students attained conceptual level raising. Each of the tests consisted of 13 questions, with a maximum score of 46 points. As we see in Table 1, the two condition groups were comparable on pretest results (that is how they were constructed) with the mean score of 9.31 points showing that the students had sufficient prior knowledge at their disposal.

The difference between pretest and posttest in both conditions showed that, on average, students' learning results improved $(t=6.367, d f=51, p<0.001)$.

We compared the results of the posttest for the process and the product groups using a $t$ test. The test showed that the results of the two groups did not differ significantly $(t=0.75$, $d f=50, p>0.05)$. This was confirmed by a covariance analysis with the pretest as a covariate, which showed no significant difference in the two means of the posttest between the two conditions $(F[1,49]=1.43, p>0.05)$.

The posttest measured level raising for four topics and the total score on the posttest consisted of the sum of the score on prior knowledge for Counting Routes in a Grid, Calculating Probabilities in a Grid, Solving Counting Problems with a Grid and Solving Probability Problems with a Grid. Each concept was represented by two questions. In order to have a closer look at the level raising taking place in both condition groups, we analysed for both condition groups how many students attained the conceptual level for each topic.

Table 1 Mean and standard deviation of pretest and posttest in both conditions

\begin{tabular}{llllll}
\hline Condition & $N$ & \multicolumn{2}{l}{ Pretest } & & \multicolumn{2}{l}{ Posttest } \\
\cline { 5 - 6 } & & Mean & $S D$ & Mean & $S D$ \\
\hline Process help & 26 & 9.38 & 4.92 & 13.46 & 8.80 \\
Product help & 26 & 9.23 & 4.35 & 15.12 & 7.10 \\
Total & 52 & 9.31 & 4.60 & 14.29 & 8.00 \\
\hline
\end{tabular}


Table 2 The number of students who attained the conceptual level for a certain topic

\begin{tabular}{lll}
\hline Topic & Frequency & \\
\cline { 2 - 3 } \cline { 3 - 3 } & Product condition & Process condition \\
\hline Counting routes in a grid & 8 & 8 \\
Calculating probabilities in a grid & 0 & 2 \\
Solving counting problems with a grid & 1 & 0 \\
Solving probability problems with a grid & 0 & 1 \\
\hline
\end{tabular}

We counted a student as 'having reached the conceptual level' very strictly, namely when she or he got the maximum score for both questions on the topic. The example in the Appendix shows that the maximum score is given when a student has fully reached the conceptual level. A check of the pretest results showed that no student was at the conceptual level for any topic in the pretest. The results of the conceptual level analysis are shown in Table 2.

Nine students in the product condition and 11 in the process condition attained the conceptual level for a concept. In both condition groups, eight students attained the conceptual level for the concept of Counting Routes in a Grid. Both groups consisted of 26 students, so only a minority of the students attained this level. The students who attained level raising were average or high-level students. This makes clear that, on average, the learning materials were very difficult for the students in this experiment.

The role of the process teacher

What did the process teacher do and how did his behaviour affect the learning process of the students? In this section we will describe and discuss the role of the process teacher by analysing episodes from the audiotapes of the lessons; (...) indicates that words have been deleted for the sake of clarity.

In the passage below, the process teacher introduced the second lesson. In the introduction of the first lesson, he had made it clear that he was not going to help the students with the mathematics. He clarified what he expected them to do:

I want to make clear to you that my role will be a bit different from usual. So, what it is all about is that, all the time, you will try to tell one another the meaning of what you did. Show one another what you do, explain it, if you do not understand. The object of this collaboration is that you pay attention to that. That means you not only just do what you do, but also explain to one another why you do it. (...) So, if you really disagree, criticise one another. Then you say "No, that is not correct" or something similar and do not hesitate to do so. Don't think "Oh, leave it". If you really think that you disagree, say it. That's what you learn from and, ehm, then you will see that you will be able to continue. OK.

The teacher emphasised that he wanted the students to interact. He encouraged students to show their work, to explain it and to criticise one another's work. He made it clear that these are activities from which one can learn and he put his faith in the students. It turned out that many students got stuck and had nothing to discuss. Although the teacher made it 
clear that he would not help the students with the mathematical content, they did ask him a lot about the mathematics. How did he react in such a situation? Below we find an example of a typical reaction:

Student: $\quad(. .$.$) Here. . that must be 0.80$, but if we. . that 80 , no.

Processteacher: No, you have to agree about that by yourselves. He [pointing at peer student] will certainly try to convince you, I guess.

Student: The result is not $100 \%$, I think $0.8 \ldots$

Process teacher: Think about it, see if you can discover the mistake together.

I, no, you may, no, you cooperate very well...

The students wanted the teacher to give them a clue and to judge their work. The process teacher passed back the content-related questions and he put his faith in the students' own ideas. The intention was to stimulate the students to develop their own ideas. Very often this did not happen and students got frustrated, as the following episode illustrates.

Process teacher: Do you agree with one another?

Student: $\quad$ No, it is really shit because, if you get no explanation, and you don't know in which direction to go, no,...

Process teacher: Then you find out for yourselves.

Student: $\quad$ No, after some time, you are really fed up...

Process teacher: You can do it, you can really do it, I am sure because, if you carefully read the text, then you can do it.

In this passage, the process teacher stressed the importance for the students to come to an agreement about the right answer. The students were discouraged, because they did not know in which direction to go. The process teacher directed them to their own thinking. The students did not want to continue, but the process teacher encouraged them to proceed. This was a very problematic situation for the students, because they really got 'stuck' and they did not have any clue of how to proceed.

In summary, the process teacher stressed the importance of students interacting and finding out the right answer by themselves, passed back the content-related questions and put his faith in the students' own ideas. Although the process teacher made very strong efforts to stimulate students' own thinking, the majority of the students wanted the teacher to judge their work and give them mathematical hints. In the evaluation of the lessons, the teacher told us: "I found it difficult that I was not allowed to say the things that I wanted when they got stuck. I would really have liked to give them subtle hints like 'use the preceding task'."

The role of the product teacher

We now describe the role of the product teacher by analysing his utterances during the lessons. What did the product teacher do and what was the effect on the students' learning process? 
Student $R$ : This is 64 , isn't it?

Product teacher: How did you get that answer?

Student R: Well, you have five days, 1, 2, 3, 4, 5, and two days off.

And here you can choose when.

Product teacher: But can you...how can you describe that?

Student R: I don't know.

Product teacher: $\quad$ Such a week, with two free days, how can you describe that in a practical way?

Student J: $\quad$ With a tree.

Student $R$ : We have to...Pascal's triangle.

Product teacher: Yes, finally we will come to Pascal's triangle, a tree is a bit long, but imagine that you would make a string. In your day planner, if you want to write down that you are free on Tuesday and Friday, how would you describe that?

The students wanted to check their answer. Their answer was not correct. The teacher asked student $\mathrm{R}$ to explain his answer. This explanation was not correct. The teacher's criticism (unlike criticism from peers) did not encourage student $\mathrm{R}$ to justify his work. The product teacher tried to guide the students to a higher level by giving a hint. The students, however, had some difficulties in understanding this hint.

Student $N$ : $\quad$ Fred, that string, is it $7^{7}$ ?

Product teacher: Why?

Student $N$ : $\quad$ Because there are 7 beads and they all have the possibility on 7 places.

Product teacher: Not all the places are different, the blues are all blue, and the reds are all red. Try it, with your pencil.

Student N: Uh, I do not understand.

Product teacher: Whether you transpose two blue ones or not, that does not make a difference.

Student $N$ : Oh, then it must be $7^{6}$.

The students asked the teacher to judge their work. The product teacher asked the students to explain their work. The explanation of the students was not completely correct. The product teacher criticised the part of their work that was not correct and provided a hint. The students did not understand the hint and they guessed what the correct answer could be. Subsequently (this is not part of the transcript as shown above) the product teacher then asked them to have a look at the previous tasks. The students realised that they had skipped some tasks and they set to work on them. As we can see, the product teacher criticised the students' work without directly telling them the correct answer. He directed them to the previous tasks in order to let them make the link and build up the correct answer by themselves: 
Student M: $\quad$ Fred, is this 2 to the power of 8 or not?

Product teacher: In total? No,...

Student R:

The question is "How many routes are going to the box with 100 points?',

Product teacher: They say: "Hint: use task 8.' What is task 8 about?

Student R:

Yes, then we did this...2 to the power of

Product teacher: What do these numbers mean?

Student M:

There are this many routes to this, five...

Product teacher: How many routes to this point?

Student R: Yes

Product teacher: What does a route look like?

Student M: $\quad$ Like this, or like this.

Product teacher: Yes, like this, but always...? [Asks to complete]

As in the previous examples, the students checked their work by asking the teacher. This time, the product teacher criticised the answer directly and referred students to the previous task. When the students made it clear that they had already considered the previous task, the product teacher simplified the task by splitting it up into small questions. He asked the student to complete his sentence, as if it were a little riddle. The product teacher provided very extended, although fragmented, help. From this passage, we cannot judge whether student $\mathrm{R}$ really profited from this teacher intervention.

In summary, when the students asked the teacher to judge their work, the product teacher made them show and explain their work. When he criticised (implicitly or explicitly) their work, however, they were not stimulated to create their own mathematics and to alter their self-image ("we are no mathematicians"). The interactions between teacher and students were extensive and therefore students sometimes had to wait. In order to provide all students with his help, the product teacher would have liked to give some traditional instruction when the many students encountered a problem. In general, as the passages above show us, the help of the product teacher took more time than the help of the process teacher.

\section{Students' experiences}

At the end of all of the lessons, we asked the students whether they had any hints for improving the lessons. In the process groups, seven out of 13 pairs answered that they wanted to have more explanations. One of these pairs mentioned: "We have learned nothing, because we couldn't ask anything and we only learn if we have made some mistakes and correct them and then make the test." However, another pair, consisting of two high-level students, said: "We have learned better to think for ourselves." In the product group, eight out of the 13 pairs answered that they wanted to have more explanations. One of them said: "We did not learn a lot, but we learned to cooperate and to consider the problem in a different way and to look for solutions. We did not get enough explanation and help." 


\section{Conclusion and discussion}

General conclusions and explanations for the results

We investigated what kind of teacher help was most fruitful for students who worked collaboratively with specially-developed learning materials and computer simulation. We compared help from the teacher who kept away from the mathematical content and stimulated the interaction process between students with teacher help that addressed the mathematical content of the students' work. It was questioned which kind of help would lead to more conceptual level raising. It turned out that there was no difference in level raising between both conditions. This result differed from the findings of Dekker and Elshout-Mohr (2004) who conducted a similar experiment with a different mathematics task and different level of education, namely, pre-university. In their study, teacher help that stimulated the interaction between students and kept away from the mathematical content led to more conceptual level raising for the students. In both studies, students got the same kind of instruction and students were not used to these kinds of teaching practices. Students in pre-university education easily grasped the opportunity to solve the mathematical tasks with one another (Dekker and Elshout-Mohr 2004) while, in this study, the students in senior general secondary education wanted the teacher to explain the mathematics to them. From the literature, it is known that these students were less motivated to perform research by themselves (Prent 1999; PRINT 1998). It is clear that students in this lower type of education are strongly dependent on the teacher's explanations and the teacher's external regulation, while the learning materials presuppose an investigative approach on the part of the students.

In both condition groups, the teachers provided much more help than in Dekker and Elshout-Mohr's experiment. The process teacher encouraged their collaborative investigations and the product teacher took them by the hand in regard to the content. Although the students in this study significantly attained conceptual level raising, the proportion of this level raising was not very impressive. The students improved from 9.31 on the pretest to 14.29 on the posttest, which had a maximum score of 46 points. So, although the teachers made serious efforts, the students did not attain all the learning goals.

Besides the students' difficulties with the learning materials, we question the interaction with their peers. The students were working in couples and this appeared not to be sufficient for a lively collaboration on a difficult subject. They missed new 'input' when they got stuck. The reason for choosing dyads and not groups of three or four students was a practical one. Two students could work with one computer, whereas three could not. A solution for future research might be to create opportunities for peer-groups to share their questions and ideas.

Although the sample size was not very large, we do not expect that a larger sample size would lead to different outcomes. Furthermore, it might be that different students received or perceived the help in a different way. In future research, it might be interesting to focus on the differences between students' perceptions in relation to the help that the teacher provides. Besides, in our study, we did not measure the maintenance effects of the lessons.

Process or product: How to proceed?

Analysis of the posttest results did not provide us with a recipe for optimal help. Could the observation and analysis of the lessons give us a clue? We analysed the observations from 
the researcher and the teacher interviews with some samples from the audiotaped teacherstudents interactions and we came to the following conclusions below.

In the process help condition, many students really got stuck when it became difficult and they asked the teacher for help. It turned out that, when students had difficulties with the learning materials, process help did not help to evoke key activities. Both students hardly had any work or ideas to show, so the process of collaboration had already stopped. In the product help condition, the teacher invited students to show and explain their work. A question or criticism from the teacher, however, does not have the same effect as a question or criticism from a peer. When the teacher criticises a student's work, a student knows that his or her answer is wrong. When the work is criticised by a peer, a student is challenged to prove that she or he is right. So the product teacher did not evoke the performance of key activities in his direct interaction with the students. What did happen in the product condition was that students, who were waiting for help from the teacher, meanwhile explained the task to their peers. Thus, product help unexpectedly fostered the performance of some key activities (namely explanations) by students.

When the students were struggling with a difficult task, both the process teacher and the product teacher wanted to provide more explanations than their role allowed them to. The process teacher wanted to give some mathematical hints and the product teacher wanted to insert some whole-class instruction. Nevertheless, the condition group for which the teacher gave explanations did not perform significantly better than the one for which the teacher did not explain the content matter.

Concerning the possibility of combining process help and product help, we are afraid that, if both types of help are offered, students will relapse into their habitual behaviour of leaning on the teacher for explanations, especially as these students do not see themselves as full-fledged mathematicians. So, we think that a combination of both types of help should be considered very carefully.

The question of what type of help works best for students for constructing their own mathematical knowledge is not yet answered. We know that, although both teachers and students think of the teacher as a source of information, this does not increase the students' ability to create their own mathematics. Students might be reluctant to do so, because they are not confident of their own mathematical abilities. Therefore, presenting students with mathematical situations in which they already have acquired a certain level of expertise (e.g. by having them explain basic mathematics principles to younger students) could help them to gain self-confidence. This, in turn, might help students to rely on their own ideas in their own mathematical lessons and to profit more from the help of the teacher.

Acknowledgements This research was funded by NWO, the Dutch National Science Foundation, under grant no. 575-36-03 A. The opinions expressed do not necessarily reflect the views of the Foundation. We thank Alfred Gouw and Fred Pach, mathematics teachers at the Montessori Lyceum in Amsterdam, for their dedicated participation in this research project. We wish to thank Marcel Veenman for his support and valuable comments on an earlier version of this article.

\section{Appendix}

An example of a question on the subject of Routes and Probabilities is shown in Fig. 2.

A possible answer to this question is: "There are five boxes, so the probability of falling into the middle box is $1 / 5$." This answer is in line with the students' prior knowledge, but it neglects the fact that the probability to reach a box is not equal for all five boxes. With 
Fig. 2 A question on calculating probabilities in a grid from the posttest
A ball is falling in the pinball machine. What is the probability that it will fall into the middle box? Show how you arrived at your answer.

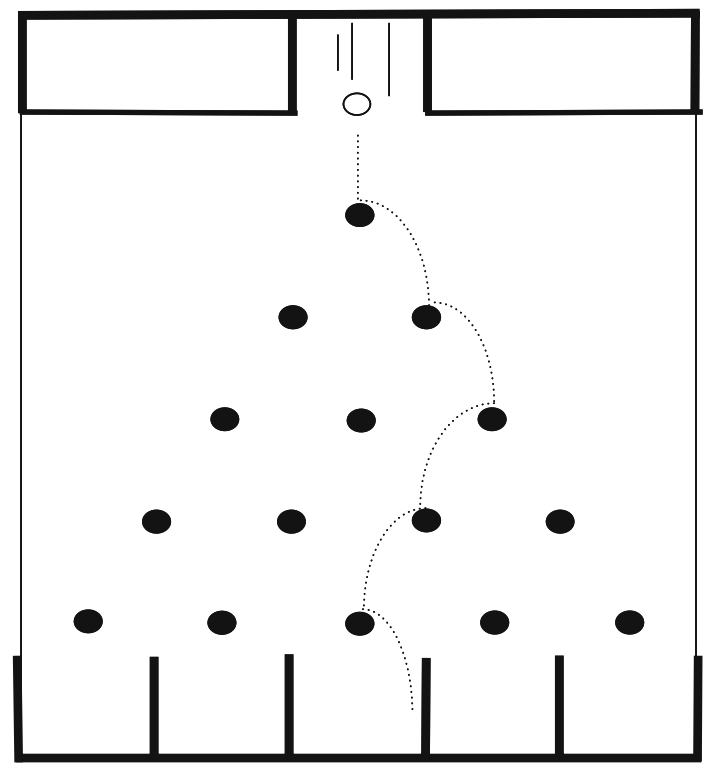

respect to the concept of Calculating Probabilities in a Grid, it is an answer at the perceptual level. This answer is rewarded with one point.

At the conceptual level, one can solve this problem by counting routes, as we see in Fig. 3. The answer would be: "There are 16 routes to all five boxes and six routes to the middle box. The probability is 6/16." This answer was rewarded with four points.

Fig. 3 Counting routes

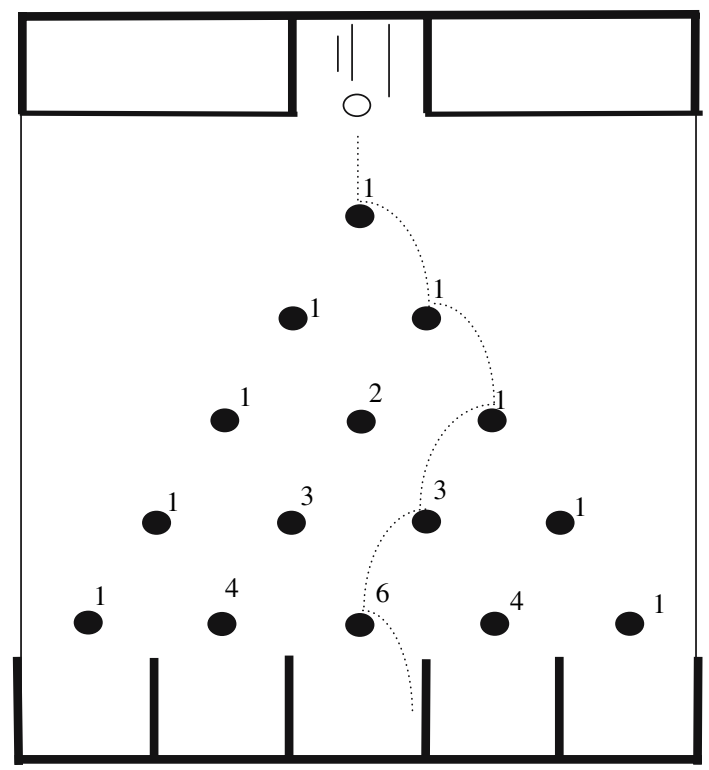


Possible answers that were rewarded with two or three points are: "The probability is more than $1 / 5$ " or "The probability is $1 / 2 \times 1 / 2 \times 1 / 2 \times 1 / 2$ " or "There are six routes to the middle box" (without calculating the probability).

The previous question was an example for the concept of Calculating Probabilities in a Grid. The pretest and posttest consisted of items for four concepts, two questions for each concept.

\section{References}

Brodie, K. (2001). Teacher intervention in small-group work. For the Learning of Mathematics, 20(1), 9-16.

Davidson, N. (1990). Cooperative learning in mathematics. Menlo Park, CA: Addison-Wesley.

Dekker, R. (1994). Graphs, small groups and the process of level raising. In A. Antibi (Ed.), Représentations graphique et symbolique de la maternelle é l'université, Tome 1 [Grahic and symbolic representations from kindergarten to university, Volume 1] (pp. 184-189). Toulouse, France: Université Paul Sabatier.

Dekker, R., \& Elshout-Mohr, M. (1998). A process model for interaction and mathematical level raising. Educational Studies in Mathematics, 35, 303-314.

Dekker, R., \& Elshout-Mohr, M. (2004). Teacher interventions aimed at mathematical level raising during collaborative learning. Educational Studies in Mathematics, 56(1), 39-56.

Hoek, D. (1998). Social and cognitive strategies in co-operative groups: Effect of strategy instruction in secondary mathematics. Unpublished doctoral dissertation, Graduate School of Teaching and Learning, University of Amsterdam, The Netherlands.

Hoek, D., \& Seegers, G. (2005). Effects of instruction on verbal interactions during collaborative problem solving. Learning Environments Research, 8, 19-39.

Hughes, M., \& Greenhough, P. (1995). Feedback, adult intervention, and peer collaboration in initial logo learning. Cognition and Instruction, 13, 525-539.

Kramarski, B., Mevarech, Z. R., \& Arami, M. (2002). The effects of metacognitive instruction on solving mathematical authentic tasks. Educational Studies in Mathematics, 49, 225-250.

Marzi, V. (2003, August). Cooperative learning and theoretical thinking: An experimental study in primary school. Paper presented at the Tenth European Conference for Research on Learning and Instruction, Padova, Italy.

Niemiec, P., Sikorski, C., \& Walberg, H. (1996). Learner-control effects: A review of reviews and metaanalysis. Journal of Educational Computing Research, 15, 157-174.

Pijls, M., Dekker, R., \& Van Hout-Wolters, B. (2003). Mathematical level raising through collaborative investigations with the computer. The International Journal of Computers for Mathematical Learning, $8,191-213$.

Prent. (1999). Reports of meetings with teachers who participated in the project 'Praktische Opdrachten en Nieuwe Technologieën' ['Investigation Tasks and New Technologies']. Utrecht, The Netherlands: Freudenthal Institute.

PRINT. (1998). Reports of meetings with teachers who participated in the project 'Project Invoering Nieuwe Technologieën' ['Project Implementation of New Technologies']. Utrecht, The Netherlands: Freudenthal Institute.

Schnackenberg, H. J. (2000). Learner control over full and lean computer-based instruction under differing ability levels. Educational Technology, Research and Development, 48(2), 19-35.

Van Hiele, P. M. (1986). Structure and insight. Orlando, FL: Academic Press.

Veenhoven, J. (2004). Begeleiden en beoordelen van leerlingonderzoek: Een interventiestudie naar het leren ontwerpen van onderzoek in de tweede fase bij aardrijkskunde [Teaching and assessing students' research: A study on supporting learning to make a research design in upper secondary geography education]. Enschede, The Netherlands: PrintPartners Ipskamp.

Webb, N. M. (1991). Task-related verbal interaction and mathematics learning in small groups. Journal for Research in Mathematics Education, 22, 366-389.

Wood, T. (2001). Teaching differently: Creating opportunities for learning mathematics. Theory into Practice, 40, 110-117. 